\title{
Las Estrategias de Inserción Económica Internacional de Colombia: Una Valoración de la Inversión Extranjera Directa y de los Tratados De Libre Comercio*
}

\author{
Germán C. Prieto ${ }^{1}$ \\ ${ }^{1}$ Profesor Asociado del Departamento de Relaciones Internacionales de la Facultad de Ciencia Política y \\ Relaciones Internacionales. Pontificia Universidad Javeriana. Bogotá, Colombia. \\ E-mail: gcprieto@@googlemail.com \\ Eloísa Cardona ${ }^{2}$ \\ ${ }^{2}$ Licenciada en Relaciones Internacionales. Facultad de Ciencia Política y Relaciones Internacionales. \\ Pontificia Universidad Javeriana. Bogotá, Colombia. \\ E-mail: eloisacardona1996@gmail.com
}

\section{INTRODUCCÍON}

$\mathrm{D}^{\mathrm{s}}$ esde finales de los años 1980 Colombia comenzó a adoptar un modelo económico neoliberal, bajo el cual ha implementado dos estrategias principales de inserción económica internacional (ESIEI), como son la atracción de inversión extranjera directa (IED), y el acceso de sus exportaciones a mercados internacionales. Mientras que la primera estrategia se ha mantenido homogénea a lo largo de los diferentes gobiernos, la segunda, en particular la firma de tratados de libre comercio (TLCs), ha variado durante los casi 30 años de neoliberalismo que lleva el país. Después de una primera etapa donde Colombia

"El inicio de esta investigación tuvo lugar en la estancia de investigación (Visiting Fellowship), que Germán C. Prieto realizó en el German Institute of Global Area Studies (GIGA) en Hamburgo (Alemania) en julio de 2015, como parte del Proyecto Procol "Colombia de cara a la Proyección de Poder de Brasil", liderado por Eduardo Pastrana (Ponitificia Universidad Javeriana, Colombia) y Daniel Flemes (GIGA). En esta estancia, las discusiones con el colega Jorge Garzón fueron de gran utilidad para perfilar la investigación, dado que parte de sus primeros avances sirvieron para publicar un trabajo conjunto. Una versión inicial del presente artículo fue presentada por Germán C. Prieto en el Taller "Estado del Arte de la Economía Política Internacional (EPI) en Latinoamérica", realizado en la Universidad del Rosario (Bogotá) en noviembre de 2016. El autor desea agradecer a Ralf Leiteritz por esa invitación, y en particular a Diana Tussie por sus valiosos comentarios. La vinculación de Eloísa Cardona como coautora en la etapa definitiva del trabajo, para completar la actualización y análisis de los datos, fue crucial para terminar la versión final del artículo.

DADOS, Rio de Janeiro, vol.65 (1): e20200013, 2022

https://doi.org/10.1590/dados.2022.65.1.254 
optó por una estrategia de bloque, como lo era la Comunidad Andina (CAN), para liberalizar su comercio con la región y con el mundo, con el estancamiento de este proyecto regional, a comienzos de la década de los 2000, emprendió una estrategia de diversificación de sus acuerdos comerciales de manera individual.

Este artículo mostrará que aunque las ESIEI de Colombia han sido consistentes con el neoliberalismo, en términos de mantener el objetivo de profundizar la liberalización económica, de incrementar el acceso a mercados y de aumentar los flujos de IED, también han sido dispersas, porque no han tenido un impacto significativo sobre el desarrollo económico en términos de una mayor generación de empleo y de producción y exportación de mayor valor agregado. En lugar de contribuir a la transformación productiva, hacia una mayor industrialización y aumento de las exportaciones no tradicionales y no minero-energéticas, la IED ha llegado sobre todo al sector minero-energético, y la firma de TLCs - después de haber asegurado el acceso a mercados de socios tradicionales - no ha seguido criterios claros que alejen a Colombia de la presión de la reprimarización.

Estos argumentos se desarrollarán en tres partes. La primera revisa las políticas que Colombia ha adoptado para atraer mayores flujos de IED y reflexiona sobre el impacto de estos últimos sobre el crecimiento y la reprimarización de la economía colombiana. La segunda analiza la estrategia de firmar TLCs sin criterios claros, haciendo énfasis en las oportunidades que los diversos socios ofrecen como destino de las exportaciones no minero-energéticas del país. Finalmente, la conclusión señala la dispersión que ha caracterizado las ESIEI de Colombia y el escaso impacto que han tenido sobre el desarrollo económico. Aparte de proporcionar una evaluación de las ESIEI de Colombia en los últimos 30 años, otra contribución significativa del presente artículo radica en el ejercicio de agregar cifras y datos de distintas fuentes para obtener un panorama general del comportamiento de la IED, así como una valoración de la importancia de los socios comerciales con los que se han firmado TLCs como destino de exportaciones no minero-energéticas, lo cual no es posible encontrar en una misma fuente en la literatura disponible hasta el momento. 


\section{POLIITICAS DE ATRACCIÓN DE IED EN COLOMBIA: DESEMPEÑO, IMPACTO SOBRE EL CRECIMIENTO ECONÓMICO Y REPRIMARIZACIÓN}

Este apartado comienza repasando las principales políticas que el Estado colombiano ha implementado desde los años 1990 para atraer IED. Posteriormente se mostrará que, si bien Colombia ha tenido un buen desempeño en cuanto a atracción de IED dentro del contexto regional, el impacto de los flujos de IED sobre el crecimiento y el desarrollo económicos son de una parte magros, y de otra poco claros. Esto servirá para argumentar sobre la precaria inserción económica internacional de Colombia, en términos de sus efectos sobre el desarrollo económico nacional.

\section{Políticas y evaluación de desempeño de Colombia en materia de IED}

Las políticas de atracción de IED durante la etapa actual de neoliberalismo en Colombia pueden clasificarse en dos periodos: el primero, de 1990 a 2005, en el cual se desarrollaron las políticas relativas a la implementación de las reformas de ajuste estructural; y el segundo, de 2005 hasta hoy, caracterizado por la continuidad y profundización de algunas de estas políticas. El incremento en los flujos de IED durante los años 1990 se debió fundamentalmente a la apertura económica, que implicó una baja generalizada de aranceles y facilidades para la exportación, y a reformas de ajuste estructural como las políticas de privatización de empresas públicas y de flexibilización del mercado laboral (Garavito, Iregui y Ramírez, 2012:29). Algunos cambios sustanciales en el nuevo régimen de inversiones con respecto a las condiciones proteccionistas del pasado se dieron a través de la Ley 9 de 1991, que garantizó la igualdad entre inversionistas extranjeros y nacionales, permitió la entrada libre de IED a la mayoría de los sectores de la economía, otorgó a los inversionistas extranjeros acceso al crédito interno y eliminó las restricciones al giro de utilidades y a los reembolsos de capital (Garavito, Iregui y Ramírez, 2012:29).

Durante esta etapa Colombia firmó acuerdos bilaterales de inversión con México, Perú, Reino Unido, Italia y Cuba en 1994, y con Chile en 2000, de los cuales sólo entraron en vigencia los acuerdos con México (en 1995) y con Perú (en 2004) (MinCIT, 2019a)' ${ }^{1}$, debido a objeciones de la Corte Constitucional de Colombia frente a temas de expropiación y compensación (De Lombaerde y Garay, 2009:10). En estos años Colom- 
bia también se asoció a varios centros y acuerdos internacionales, como el Centro Internacional de Arreglo de Conflictos Relativos a Inversión (CIADI), el Organismo Multilateral de Garantía de Inversiones (MIGA7) y el Fondo Multilateral de Inversiones (Alfonso, 2012). También se creó la oficina de Proexport, encargada de promover a Colombia como destino de inversión, lo que se consideró un factor determinante en el incremento de los flujos de IED al país durante los años 1990 (Mejía, 1998, citado en Garavito, Iregui y Ramírez, 2012:29). Estos cambios en la regulación y los nuevos tratados bilaterales de inversión, junto con la creación de Proexport, generaron una estructura institucional más amigable con la IED, en concordancia con las disposiciones del modelo neoliberal.

Durante el período 2005-2010 se agotaron las reformas normativas como mecanismo para atraer IED. El gobierno colombiano buscó incentivar la IED a través de la estabilidad normativa y las exenciones tributarias, la primera relacionada con los contratos de estabilidad jurídica y la segunda con el establecimiento de zonas francas (Garavito, Iregui y Ramírez, 2012:32), con lo cual la agencia Proexport (hoy ProColombia) comenzó a enfocarse en atraer IED a sectores no tradicionales (Kalin, 2009:13-16). Durante la última década Colombia ha suscrito acuerdos bilaterales de inversión (BIT) ${ }^{2}$ con Francia, Singapur, Turquía, Japón, China, India, Perú (BIT profundizado), España, Suiza, Reino Unido y Japón, de los cuales sólo los cuatro primeros están aún pendientes de entrar en vigencia (SICE, 2019). Los TLC con México, Chile, Estados Unidos (EE.UU)., European Free Trade Association (EFTA), Canadá, Triángulo Norte (Salvador, Guatemala y Honduras) y Corea del Sur incorporan también un capítulo de liberalización de inversiones ${ }^{3}$.

Después de haberse mantenido por debajo de los US\$ 2 billones desde los años 1980 hasta mediados de los 1990, en 1996 la IED en Colombia superó por primera vez esta barrera, alcanzando picos de casi US \$6 billones en 1997 y superando los US\$ 10 billones en 2005 y en 2008 (Garavito, Iregui y Ramírez, 2012:25). Mientras que en 2009 la IED se redujo a US\$ 8 billones, y en 2010 a US\$ 6,4 billones, el repunte de la IED en la primera mitad de esta década fue fenomenal, llegando a duplicarse con respecto a 2009: US\$14,6 billones en 2011, US\$ 15 billones en 2012, US\$ 16,2 billones en 2013 y US\$ 16,3 billones en 2014 (CEPAL, 2016:49). Sin embargo, a partir de 2015 se presentó un descenso sustancial a US\$ 11,7 billones, con un leve repunte a 13,8 billones de dólares en 2016 y en 2017, pero cayendo nuevamente a 11 billones 
para el año 2018 (Banco de la República, 2018a). Para el año 2011, el acervo de IED ascendió a US\$ 97,3 billones (CEPAL, 2016:89), cifra equivalente al $29 \%$ del PIB, y que representaba un crecimiento nominal del 600\% con respecto a lo observado en marzo del año 2000 (Garavito, Iregui y Ramírez, 2012:36), año en que el acervo de IED representaba apenas el 13\% del PIB (Kalin, 2009:26). Durante la segunda década del presente siglo el acervo de IED para Colombia continuó ascendiendo de forma sustancial, pasando de US\$ 112,9 billones en 2012, a US\$ 149,7 billones en 2015 (CEPAL, 2016:89) y US\$188,7 billones en 2018 (CESLA, 2019:7), lo que representó el 30\% (2012), 51\% (2015) y 59\% (2018) del PIB, respectivamente.

Sin embargo, con todo el aumento de la IED a lo largo de los años de neoliberalismo, el desempeño de Colombia en materia de atracción de IED con respecto a otros países de América Latina no ha sido muy satisfactorio. Entre 2000 y 2015, Colombia se ubicó en el cuarto lugar dentro de los principales destinos de IED en América Latina (por debajo, en su orden, de Brasil, México y Chile), siendo superado por Argentina tan solo en 2010 y 2012. Sin embargo, en ese mismo periodo representó un promedio de apenas entre 7\% y $8 \%$ como destino de IED en América Latina, con una diferencia de 3-4 puntos porcentuales con respecto al tercer país destino, Chile, que en promedio obtuvo el $11 \%$ del total de IED que ingresó en la región ${ }^{5}$. Así, tenemos a Colombia como uno de los principales destinos de IED en la región, pero con una participación muy pequeña dentro del total. Esta valoración puede refinarse observando índices más sofisticados sobre la atracción de flujos de IED por parte de Colombia en comparación con otros países de América Latina, aunque para años menos recientes.

De acuerdo con el índice de desempeño y el índice de potencial de atracción de IED (Garavito, Iregui y Ramírez, 2012:39-41), en el periodo 2003-2009 Colombia ocupó una posición de país "por debajo de su potencial" (PDP), esto es, un país con entradas efectivas de IED por debajo del promedio mundial y potencial de atracción por encima del promedio mundial. Refiriéndose a los puestos que ocupó Colombia dentro de un total de 141 países para los cuales la UNCTAD calculó ambos índices ${ }^{6}$, Colombia ocupó lugares inferiores a los de países como Chile, Costa Rica, Honduras, Nicaragua, Panamá, Perú y Uruguay, los cuales presentaron un mejor índice de desempeño. Con respecto al índice de potencial de atracción, Colombia se ubicó en lugares inferiores a los de Argentina, Brasil, Chile, México, Panamá, Uruguay y 
Venezuela; similares a los de Bolivia, Costa Rica, Ecuador y Perú; y tan solo superiores a los de El Salvador, Guatemala, Honduras, Nicaragua y Paraguay.

Así, tenemos entonces que Colombia ha tenido un relativo éxito en la atracción de IED durante los años de neoliberalismo, al haberse posicionado dentro de los cuatro principales destinos de IED en la región. Sin embargo, su escasa participación en el total de flujos de IED hacia América Latina y su ubicación en un rango medio de los índices de desempeño y de potencial de atracción en la región, obligan a concluir que, en términos generales, el desempeño de Colombia como destino de IED en América Latina no ha sido muy destacado. Para complementar esta valoración, es necesario reflexionar sobre el impacto de la IED sobre el crecimiento y el desarrollo económico en Colombia.

\section{IED, crecimiento y desarrollo en Colombia}

Aunque los estudios de impacto de la IED sobre el crecimiento económico en Colombia son más bien escasos, en esta sección se recurre a algunos de ellos para dar cuenta de una valoración general. Mientras que entre 1993 y 2003 la IED representó un promedio anual del 2.3\% del PIB, entre 2004 y 2010 este promedio fue de 4\% (Garavito, Iregui y Ramírez, 2012:25), el cual se mantuvo (4.2\%) para el periodo 2012$2018^{7}$. Es interesante observar que el aumento más que duplicado de los montos totales de IED hacia Colombia entre 2011 y 2014 con respecto a 2010 no se corresponde del todo con el incremento del PIB, que pasó de US\$287, 1 billones en 2010 a US\$ 335,4 billones en 2011, US\$ 369,4 billones en 2012, US\$ 380 billones en 2013 y US\$ 378 billones en 2014 (Banco de la República, 2015). Mientras que entre 2011 y 2014 la IED aumentó en promedio cerca de un $140 \%$, el PIB lo hizo en un $27 \%{ }^{8}$. En cambio, en los años posteriores, en los que se ha presentado una disminución tanto de la IED como del PIB, la relación se corresponde con mucha exactitud. Entre 2015 y 2018 la IED disminuyó sustancialmente, situándose en US $\$ 11,7$ billones en 2015, US\$ 13,8 billones en 2016 y 2017, y US\$ 11 billones en 2018, es decir, una disminución promedio de $23 \%$ con respecto a la IED recibida en 2014 (el tope histórico de la IED en Colombia) ${ }^{9}$. Por su parte el PIB disminuyó significativamente hasta alcanzar los US\$292 millones en 2015 y los US\$ 280 billones en 2016, recuperándose a US $\$ 309$ billones en 2017 y hasta los US $\$ 317$ billones en 2018, lo que representa en promedio una disminución de $22 \%$ con respecto al PIB de $2014^{10}$. 
De acuerdo a estimaciones de Fedesarrollo (2007:46-48), en el periodo 2001-2006 la IED aportó entre $0.7 \%$ y 1.7\% al crecimiento del PIB en Colombia (y, en general, un promedio de $1 \%$ anual entre 2002 y 2007). Si se tiene en cuenta que en estos años el PIB creció a un promedio del $5 \%$ anual ${ }^{11}$, tendríamos que la IED explicaría en promedio algo más de una quinta parte de ese crecimiento, lo cual no es poco. Sin embargo, considerando que el crecimiento del PIB per cápita en este mismo periodo fue de $3,7 \%$ en promedio ${ }^{12}$, tendríamos que la IED, si bien fue un importante jalonador del crecimiento del PIB en estos años, no fue tan determinante como para implicar un cambio drástico en el crecimiento del PIB de Colombia que se tradujera en un aumento sustancial del PIB per cápita nacional. El estudio de Reina (2016:26) concluye algo similar para el periodo 2007-2014, en el que la IED aportó en promedio un $0.78 \%$ al crecimiento anual del PIB. Sin embargo, dado que en estos años el PIB creció a una tasa promedio del $4.5 \%$, tendríamos que la IED estaría explicando menos de una quinta parte de dicho crecimiento, es decir, perdiendo su importancia para el crecimiento económico colombiano pese al aumento significativo de la IED entre 2011 y 2014. Al igual que lo observado en el lapso 2002-2007, el PIB per cápita creció en promedio 3.1\% entre 2007 y 2014 $4^{13}$, con lo que se demuestra que el crecimiento del PIB y de la IED no tuvieron un efecto tan relevante sobre el aumento del PIB per cápita nacional.

Esta reflexión abre una pista para pensar que, bajo el modelo neoliberal, la economía colombiana no ha logrado que la IED sea una fuente de financiamiento que aumente el crecimiento económico, en la medida en que la estimación de Fedesarrollo establece que la IED explicaría como mucho una quinta parte del crecimiento del PIB en el periodo analizado ${ }^{14}$. Más aun, el crecimiento de la economía colombiana, en el que la IED ha jugado un importante papel, no se ha traducido en un aumento significativo del PIB per cápita, con lo que ni el crecimiento del PIB, ni con ello la IED, han sido suficientes para generar un aumento significativo en el ingreso nacional dividido entre el número de habitantes ${ }^{15}$. En este sentido, puede pensarse que el modelo económico no ha logrado funcionar de la forma en que se lo proponía ni ha dado los frutos esperados en términos de aumento de la riqueza nacional.

En lo que tiene que ver con el desarrollo, entendido como el mejoramiento de las condiciones de vida de las personas traducido en un mayor bienestar (y para lo cual se requiere un aumento significativo de 
sus ingresos), es necesario realizar actividades productivas cuyo valor agregado permita dicho aumento. Por desgracia, la concentración de la IED en el sector minero-energético no ha contribuido a las necesidades de trasformación productiva de la economía colombiana. El sector de petróleo y minería fue el principal destino de la IED entre 1990 y 2010, alcanzando picos de concentración cercanos al 70\% en 1992, al 60\% en 2004 y 2006, y superando nuevamente el 70\% en 2009 (Garavito, Iregui y Ramírez, 2012:26). Entre 2012 y 2014 este sector fue destino de un promedio anual del $48 \%$ del total de IED recibida por Colombia, registrando una disminución al 40\% en $2014^{16}$. En los años entre 2015 y 2018, la participación del sector petrolero y minero-energético se presenta un promedio de $27 \%$, cuyo valor más alto se da en 2014 con $39 \%$ y el más bajo en 2016 con 16\%, aunque en 2018 alcanza un valor similar al del 2014, llegando a un $37 \%{ }^{17}$. A pesar de lo anterior, durante este período de análisis el porcentaje de IED destinada al sector petrolero y minero-energético nunca se acerca a los valores alcanzados durante los años 1990, cuando rondaba un 70-60\%.

Por su parte, la industria manufacturera ha sido un destino inferior de la IED, alcanzando picos cercanos al 50\% en 1995, y al 30\% en 1998 y en 2006 (Garavito, Iregui y Ramírez, 2012:26), pero cayendo estrepitosamente a un promedio de 16\% entre los años 2012 y 2014 (Prieto y Defelipe, 2015:195) ${ }^{18}$. Entre 2015 y 2018 el promedio de la participación del sector manufacturero en la IED del fue del 15.5\%, alcanzando un tope de $23 \%$ en 2015 y un piso de $8 \%$ en $2018^{19}$. El sector de servicios se ubicó como el segundo destino de la IED en Colombia entre 1997 y 2000, alcanzando picos cercanos al 50\%, y disminuyendo luego su participación a niveles que promediaron cerca del 35\% hasta 2010, llegando a sus niveles más bajos en 2006 y 2009, cuando fueron inferiores al 20\% (Garavito, Iregui y Ramírez, 2012:26 y 29). En los años posteriores hasta el 2014, este sector sumó un promedio anual de $34 \%{ }^{20}$, con lo que permaneció como el segundo destino de IED por sectores agregados de la economía ${ }^{21}$. En cambio, en el periodo 2015-2018, el sector servicios se convirtió en el primer destino de IED en Colombia, ocupando en promedio el 51\% del total de IED recibida (con un tope en 2016 del $68 \%$ y un piso en 2015 del 49\%), destacándose los sectores de servicios financieros y empresariales, y de transporte, almacenamiento y comunicaciones ${ }^{22}$. 
Tenemos entonces que después de haber ocupado un lugar algo inferior al del sector minero-energético como destino de IED durante la década de 1990, la industria manufacturera fue desplazada significativamente por dicho sector en la década de 2000, lo que se muestra acorde con el proceso de reprimarización de la estructura productiva y exportadora colombiana que se viene dando desde hace varias décadas, y que se ha acentuado en la última (Prieto y Defelipe, 2015:195). Desde 1970 se viene presentando un proceso de desindustrialización de la economía nacional que se acentuó particularmente desde la apertura económica que se desarrolló bajo el modelo neoliberal en los años 1990 (Martínez, 2011) 23. Entre 1992 y 2007, el ritmo de crecimiento del número de plantas industriales fue negativo $(-0,55 \%)$, con lo que se cerraron más plantas de las que se crearon (Martínez, 2011:58). La industria manufacturera pasó de una tasa de crecimiento anual de $6.6 \%$ en la década de los años 1970, a $-0.1 \%$ en los 1990. Entre 2000 y 2009 hubo una recuperación notable con una tasa promedio anual de $4.5 \%$, pero el peso del PIB manufacturero en el PIB total cayó de un valor máximo de $18.5 \%$ en 1974, a niveles mínimos de $12.5 \%$ en 1999 . En el periodo de 2000 a 2009 esta participación osciló entre el 13\% y el 14\%, siendo de 13\% en el 2009 (Martínez, 2011:60 y 110). En la segunda década del siglo XXI, esta señal de desindustrialización empeoró, pues entre 2010 y 2018 el PIB industrial correspondió a un promedio de $12.7 \%$, teniendo su pico en $2010(13.7 \%)$ y su piso en $2018(12.1 \%)^{24}$. En este periodo la tasa de crecimiento promedio de este sector se ubicó en $4.5 \%$ anual, pero llegó a registrar un crecimiento incluso negativo $(-1.1 \%)$ en $2017^{25}$.

Esto contrasta con el dinamismo del sector minero-energético, que entre 1970 y 2010 presentó un crecimiento promedio de $6.9 \%$, por encima del $2.6 \%$ de la agricultura, del $3.4 \%$ de la industria y del $4.0 \%$ promedio del PIB (Martínez, 2011:60). Entre 2011 y 2018 este sector presentó un ritmo de crecimiento promedio de $4.3 \%$, con oscilaciones muy fuertes entre el pico de $49.8 \%$ de 2011 , un piso de crecimiento negativo de $-25.9 \%$ en 2015, y una recuperación de crecimiento de $17.3 \%$ en $2018^{26}$. En cuanto al empleo industrial, durante el periodo 1996-2010 hubo un crecimiento promedio equivalente a $2.1 \%$, pasando de 2.052.771 empleos en 1996, a 2.662.618 en 2010 (Prieto y Defelipe, 2015:191). Sin embargo, y pese a que el sector manufacturero mantuvo una participación del $13.5 \%$ en promedio del empleo total en este periodo, descontando la ocupación no agropecuaria ${ }^{27}$, los niveles de participación cayeron de $18.3 \%$ en 1996 a $16.5 \%$ en 2010 . Lo mismo 
ocurrió en las grandes ciudades ${ }^{28}$, donde se puede ver que la participación del sector manufacturero en la ocupación total urbana también decayó, al pasar de 20.4\% en 2001, a 18.1\% en 2010 (Martínez, 2011:6062). En el periodo 2011-2016, el empleo industrial perdió aún más participación en el empleo total, con un promedio de $12.2 \%$, alcanzando un pico de $13 \%$ en 2011 y un piso de $11.5 \%$ en $2016^{29}$, lo que refuerza la tendencia de desindustrialización sufrida en el país en estos años. En este periodo el ritmo de crecimiento del empleo industrial fue casi nulo, incluso negativo en los años 2013, 2014 y 2016, y un 2\% inferior en 2016 con respecto a $2011^{30}$.

Como lo señalan Prieto y Defelipe (2015:194-195), el estudio de Nova (2014:377) sostiene que la concentración de la IED en la explotación de recursos naturales no renovables, hidrocarburos, minas y canteras durante los últimos años explica en buena medida que la balanza comercial dé cuenta de una grave reprimarización, esto es, exportaciones tradicionales significativas, importaciones de bienes intermedios de capital y balance negativo. En conclusión, el difuso impacto que parece haber tenido la IED sobre el crecimiento en Colombia y su contribución a la reprimarización de la economía y, como se detallará en la siguiente sección, de la oferta exportadora del país, dan cuenta de un impacto precario de la inserción económica internacional de Colombia con relación a la IED. Esto constituye un primer elemento de análisis de la dispersión y del impacto difuso de las ESIEI de Colombia, el cual será complementado a continuación con la valoración de la proyección global y regional del país en términos de tratados de libre comercio.

\section{TLCS Y POSIBILIDADES DE TRANSFORMACIÓN DE LA CANASTA EXPORTADORA COLOMBIANA}

Hasta mediados de la década de los 2000 el regionalismo abierto fue el tipo de ESIEI regional que Colombia adoptó para apoyar la implementación doméstica de reformas de ajuste estructural. Primero procurando la consolidación de un mercado común al interior de la Comunidad Andina (CAN) - para lo cual se estableció una Zona Andina de Libre Comercio y un Arancel Externo Común (AEC) - y luego buscando incrementar el acceso a mercados internacionales a través del bloque andino, Colombia se mantuvo fiel a la idea de lograr una mayor inserción económica internacional sobre una base regional. Incluso en el Grupo de los 3 (G-3), Colombia involucró a su más importante 
socio comercial andino, Venezuela, y juntos establecieron un acuerdo de libre comercio con México en 1992, y posteriormente un tratado de libre comercio con el Mercosur + Chile se completó a través de la CAN (Garzón y Prieto, 2017:131). Asimismo, durante los 90 y hasta su derrumbe en 2005, las negociaciones del Área de Libre Comercio de las Américas (ALCA) fueron asumidas por Colombia a través del bloque andino, y las negociaciones del tratado de libre comercio (TLC) con EE.UU. en 2004 y con la Unión Europea (UE) en 2008 fueron iniciadas a través de la CAN (Prieto, 2016). Antes de 2006, fueron muy pocos los acuerdos comerciales que Colombia firmó de manera individual por fuera del bloque comercial andino (siendo excepciones el acuerdo con México en 1992, con Chile en 1993, con CARICOM en 1994 y con Cuba en 2000, que en todo caso fueron Acuerdos de Alcance Parcial - excepto el de México - y no tratados de libre comercio como tales).

Sin embargo, el AEC andino nunca pudo completarse debido a las múltiples excepciones que mantuvo desde su adopción en 1994, y fue definitivamente desmontado por la firma de Colombia y Perú de sus respectivos TLCs con EE.UU. en 2006, y con la UE en 2010 (Prieto, 2016:cap. 2). Por ende, desde 2006 el desarrollo del regionalismo como una ESIEI por parte de Colombia cambió sustancialmente. Si bien continuó siendo miembro de la CAN (ahora sin el objetivo de establecer un mercado común andino), el gobierno colombiano comenzó a firmar un creciente número de TLCs con diferentes países del mundo, y finalmente renovó su compromiso con la liberalización económica neoliberal a través de la creación de la Alianza del Pacífico (AP) en 2011 (Prieto y Betancourt, 2014).

En la actualidad Colombia tiene acuerdos de libre comercio vigentes con México (desde 1995), El Salvador (2010), Guatemala (2009), Honduras (2010), Nicaragua (1985), CAN (1969), Caricom (1995), Mercosur (2005), Chile (2009), EFTA ${ }^{31}$ (2010), Canadá (2010), Estados Unidos (2012), Venezuela (2012), Cuba (2001) la UE (2013), Corea del Sur (2013), Costa Rica (2013) y Alianza del Pacífico (2014). Tiene ya suscritos acuerdos con Israel y Panamá, los cuales están pendientes de ratificación, y se encuentran en proceso de negociación los acuerdos con Turquía y con Japón, y el Acuerdo sobre el Comercio de Servicios (TiSA) ${ }^{32}$. Desde el segundo gobierno de Álvaro Uribe (2006-2010), y ante la casi total liberalización del comercio con sus vecinos latinoamericanos, Colombia ha optado por liberalizar su comercio a escala global, buscando obtener un mayor acceso a mercados para sus productos. Sin embargo, 
en la presente sección se argumentará que no han sido claros los criterios de selección de estos mercados, y ante la falta de estrategias que apunten a aumentar la competitividad de ciertos productos, tampoco se vislumbra con claridad el aprovechamiento que Colombia pueda hacer de dicho acceso, al menos para mejorar su oferta exportadora en términos de valor agregado, oferta exportadora que ha mantenido una presencia predominante de productos minero-energéticos durante los años de neoliberalismo.

En 2009 el 46\% de la canasta exportadora colombiana estaba compuesta por tres productos primarios, a saber: aceites de petróleo (24.5\%), carbón y combustibles sólidos del carbón $(16 \%)$ y aceites de petróleo para otras preparaciones y de desecho (5.8\%) (Martínez y Suárez, 2011:69). Teniendo en cuenta el nivel de sofisticación de las exportaciones, la proporción de exportaciones con sofisticación promedio $^{33}$ en Colombia en 2009 estaba en 28.3\%, la cual era muy inferior al promedio de países como México (50.2\%) y Brasil (40.2\%), igual a la de Argentina (28.5\%) y superior a la de Perú $(16.4 \%)$ y Chile (6.6\%) (Martínez y Suárez, 2011:72). Para 2009 los productos primarios alcanzaban el $71 \%$ del total del valor exportado, mientras que las manufacturas basadas en recursos y de baja tecnología representaban el 20.9\%; las manufacturas de media tecnología participaban con apenas $4.2 \%$, y el restante $1.5 \%$ de las exportaciones correspondía a manufacturas de alta tecnología. Estas cifras eran inferiores a las de países con una mayor participación de productos de mediana tecnología en sus canastas exportadoras, tales como México (58\%), Brasil (16\%) y Argentina (17\%), los cuales también tuvieron un menor peso de los productos primarios y las manufacturas basadas en recursos (Martínez y Suárez, 2011:82) ${ }^{34}$. Para 2012, el 78\% de las exportaciones correspondió a bienes primarios: petróleo, carbón, ferroníquel, oro no monetario, café, flores y banano (Nova, 2014:375). Entre 2013 y 2018, estos mismos productos ocuparon en promedio el $74 \%$ del total de exportaciones de Colombia, con un pico de $78 \%$ en 2013 y un piso de 69\% en 2016; para 2018 el porcentaje de exportaciones de estos productos sobre el total fue de $73.6 \%{ }^{35}$. Así, el panorama de reprimarización de la oferta exportadora colombiana es claro.

Desde la etapa de apertura económica iniciada a finales de los años 1980, y continuando con una tendencia que venía al menos desde mediados de siglo, América Latina ha sido el principal mercado para las exportaciones no tradicionales de Colombia ${ }^{36}$. Por ello, a lo que 
se debe sumar la cercanía geográfica y cultural, parece lógico que entre 1990 y 2010 Colombia completara la liberalización comercial con todos los países latinoamericanos. En estos mercados el país ha encontrado posibilidades de exportación de productos manufacturados que han permitido el desarrollo de la industria nacional y, sobre todo, la supervivencia de la producción manufacturera durante esta etapa de apertura comercial. En efecto, entre 2000 y 2010, Venezuela, Ecuador, Perú, Brasil, México y Chile concentraron en promedio el $44 \%$ de las exportaciones no tradicionales de Colombia, frente al $25 \%$ que representó Estados Unidos, que fue el mayor país destino de este tipo de exportaciones en este periodo (Prieto, 2011:7). Esto da cuenta de la importancia de América Latina para la diversificación de las exportaciones colombianas.

A partir de 2013 el MinCIT comenzó a realizar sus cuentas de comercio exterior distinguiendo entre bienes minero-energéticos y no minero-energéticos. Es por esta razón que el análisis que se ofrece a continuación mantiene esta diferenciación, con el fin de evaluar la contribución que la firma de TLCs por parte de Colombia ha tenido para la trasformación de su canasta exportadora hacia una mayor participación de las exportaciones no minero-energéticas. Sin embargo, dentro de las exportaciones no minero-energéticas se incluyen productos como el café, el banano y las flores, que son productos de enrome relevancia dentro de la canasta exportadora colombiana, sobre todo a países considerados de "centro" o desarrollados. Con todo, en la medida en que los bienes minero-energéticos han predominado en las exportaciones colombianas, y que esta es la clasificación que ofrece las cifras más recientes sobre el tema, se asume que la información presentada a continuación puede dar un indicativo al menos de las posibilidades de reducción de la dependencia de Colombia de las exportaciones minero-energéticas, las cuales generan muy poco empleo y escasos efectos multiplicadores en la economía, pues encadenan muy pocos sectores y productores nacionales.

Las tablas que sirven como base del análisis son producto de un profundo ejercicio de procesamiento de cifras provistas por diversas fuentes, y permiten visibilizar la contribución de las exportaciones no minero-energéticas en la canasta exportadora colombiana de una forma que ninguna otra fuente encontrada hasta el momento ofrece, dados los niveles tanto de agregación como de desagregación de la información contenida en ellas. Por una parte, se presenta una 
columna que muestra la tendencia de participación de las exportaciones no minero-energéticas entre 1993 y 2014. Allí se toma el primer año como aquél que antecedió a la entrada en vigencia de la zona de libre comercio de la Comunidad Andina (CAN), que fue el primer acuerdo de libre comercio (hoy TLC) que firmó Colombia en su etapa de adopción del modelo neoliberal de apertura económica. A su vez, el último año se toma como aquél en el que culminó el boom de las commodities vivido en la primera década del siglo XXI y que, dada la composición predominantemente minero-energética de la canasta exportadora colombiana, se considera que favoreció sustancialmente este tipo de exportaciones con respecto a las no minero-energéticas. Por otra parte, las tablas enfatizan también lo ocurrido con las exportaciones no minero-energéticas en dicho año y, a partir de allí, muestran de manera detallada lo ocurrido en el periodo 2015-2018, para poder tener una visión más actual sobre los impactos de los TLCs sobre la trasformación productiva de Colombia.

La Tabla 1 presenta la información de exportaciones no minero-energéticas de Colombia a los socios comerciales latinoamericanos y no latinoamericanos con quienes tiene TLCs firmados antes de $2011^{37}$ (aunque algunos entraron en vigencia después). Estos son sus socios más tradicionales, es decir, aquellos con los que históricamente el país ha mantenido intensas relaciones comerciales, Factor que tornaba más lógico adelantar TLCs que contribuyeran a consolidar dichas relaciones. La Tabla 2, en cambio, agrupa los países con los que Colombia ha firmado TLCs a partir de 2011, y con los cuales los criterios de elección aparecen menos claros. Por último, se presentará una reflexión sobre los dos TLCs que se encuentran en proceso de negociación (Turquía y Japón), y sobre la Alianza del Pacífico, para terminar con una conclusión general sobre lo que se considera ha sido una estrategia difusa de negociación comercial por parte de los últimos gobiernos colombianos. 
Tabla 1

Exportaciones no minero-energéticas de Colombia a socios comerciales con los que firmó TLCs antes de $2011^{38}$

\begin{tabular}{|c|c|c|c|c|c|c|c|c|c|c|}
\hline 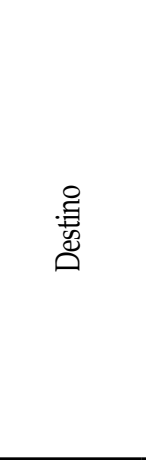 & 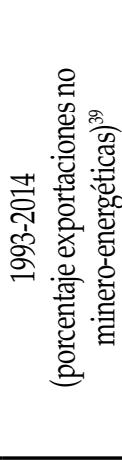 & 离 & 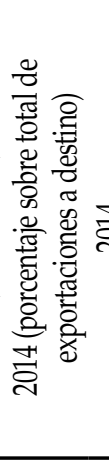 & 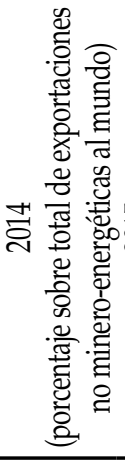 & कृ & 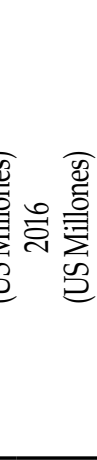 & 들 & 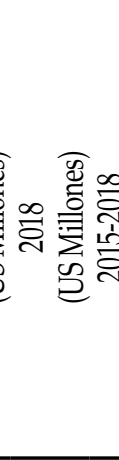 & 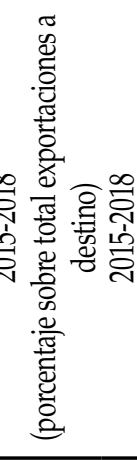 & 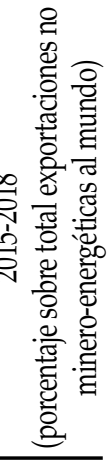 \\
\hline $\mathrm{CAN}^{40}$ & $85 \% 41$ & 2.916 & $91 \%$ & $18 \%$ & 2.503 & 2.179 & 2.444 & 2.672 & $88 \%$ & $16,5 \%$ \\
\hline Venezuela $^{42}$ & $90 \%$ & 1.590 & $90 \%$ & $9,7 \%$ & 805 & 606 & 313 & 294 & $89 \%$ & $3,7 \%$ \\
\hline México $^{43}$ & $80 \%$ & 767 & $80 \%$ & $4,7 \%$ & 806 & 861 & 879 & 873 & $73 \% 44$ & $5,5 \%$ \\
\hline Mercosur ${ }^{45}$ & $65 \%$ & 1.027 & $27 \%$ & $6,3 \%$ & 892 & 771 & 913 & 986 & $58 \%$ & $6 \%$ \\
\hline Chile $^{46}$ & $60 \%$ & 448 & $45 \%$ & $2,7 \%$ & 334 & 404 & 501 & 487 & $49 \%$ & $3 \%$ \\
\hline $\begin{array}{l}\text { Triángulo } \\
\text { Norte }^{47}\end{array}$ & $75 \%$ & 328 & $73 \%$ & $2 \%$ & 324 & 322 & 378 & 380 & $75 \%$ & $2,3 \%$ \\
\hline Canadá48 $^{48}$ & $60 \%$ & 272 & $41 \%$ & $1,7 \%$ & 258 & 278 & 302 & 309 & $57 \%$ & $2 \%$ \\
\hline EE.UU. ${ }^{49}$ & $30 \%$ & 3.848 & $27 \%$ & $23,5 \%$ & 3.796 & 3.831 & 4.031 & 4.207 & $39 \%$ & $27 \%$ \\
\hline EFTA $^{50}$ & $10 \%$ & 54 & $10 \%$ & $0,3 \%$ & 61 & 59 & 66 & 76 & $13 \%$ & $0,4 \%$ \\
\hline$U^{51}$ & $40 \%$ & 2.357 & $25 \%$ & $14,4 \%$ & 2.288 & 2.231 & 2.417 & 2.309 & $44 \%$ & $16 \%$ \\
\hline
\end{tabular}

Fuente: Elaboración propia, con base en MinCIT (2015a), DANE (2016), Procolombia (2016a), CEPEC (2017), Analdex (2018), DANE (2019a) y MinCIT (2019a).

La Tabla 1 muestra la importancia de América Latina, y en especial de la CAN, Venezuela y México, para las exportaciones no minero-energéticas de Colombia. Entre ambos países y bloque mantuvieron una tendencia superior al $80 \%$ como destino de estas exportaciones con relación a las minero-energéticas entre 1993 y 2014. Y entre 2014 y 2018 la tendencia se ha mantenido por encima del 73\%, siendo México el destino que más ha disminuido la importación de este tipo de productos colombianos con relación a los minero-energéticos, debido a las exportaciones de carbón que en años anteriores no se realizaban a este país ${ }^{52}$. Llama también la atención el desplome de las exportaciones no minero-energéticas de Colombia hacia Venezuela en 2017 y 2018, debido a la crisis económica de este último país y también en buena medida a la crisis política que ha afectado las relaciones entre ambos 
países en los últimos años. Las contribuciones del Mercosur, Chile y el Triángulo Norte también son importantes, en la medida en que entre 1993 y 2014 mantuvieron porcentajes mayoritarios como destinos de las exportaciones no minero-energéticas de Colombia. Es de resaltar que todo este conjunto de países latinoamericanos representó el $43 \%$ del total de exportaciones no minero-energéticas de Colombia al mundo en 2014, y el 37\% en el periodo 2015-2018. Esto que da cuenta de la enorme importancia que el mercado latinoamericano tiene para impulsar la trasformación de la oferta exportadora colombiana, pese a la disminución de la tendencia en los casos del Mercosur y Chile.

El panorama con Canadá, EE.UU. y Europa es muy diferente, ya que representan compradores mayoritarios de exportaciones minero-energéticas colombianas, al contrario de lo que ocurre con los países de América Latina. Restando del total de exportaciones no minero-energéticas (US \$16.363 millones) la parte que Colombia vendió a estos destinos, podemos observar que en 2014 Canadá, EE.UU. y Europa representaron el $40 \%$ del total de exportaciones minero-energéticas de Colombia al mundo ${ }^{53}$. Con todo, Canadá destaca como un importador mayoritario de productos no minero-energéticos con relación a los minero-energéticos, manteniendo una tendencia del $60 \%$ entre 1993 y 2014, que disminuye apenas al 57\% entre 2015 y 2018, pese a su caída al $41 \%$ en 2014. En cambio, EE.UU. y los bloques de la UE y EFTA compran mayores porcentajes de productos minero-energéticos que no minero-energéticos. En, cualquier caso, es destacable que EE.UU. y la UE son destinos muy importantes para las exportaciones no minero-energéticas de Colombia, dado que entre ambos representaron un 52\% de destino del total de estas exportaciones en 2014 y un $43 \%$ en el periodo 2015-2018, siendo ambos porcentajes superiores a los de América Latina en su conjunto. Esto da cuenta de los enormes beneficios que han traído los procesos de liberalización comercial con Canadá, EE.UU. y la UE para la diversificación de la oferta exportadora colombiana, los cuales contrastan claramente con la escasa participación de los países de la EFTA como destino de las exportaciones no minero-energéticas.

Es importante señalar que, mientras la tendencia de participación de exportaciones no minero-energéticas a EE.UU. sobre el total exportado se ha mantenido estable, en el caso de Canadá se pasó de un $62 \%$ y $73 \%$ de participación de estas exportaciones en 2015 y 2016, a 57\% y $36 \%$ en 2017 y 2018, respectivamente. En cuanto a la UE, aunque 
las exportaciones totales de Colombia han disminuido de US\$ 6.088 millones en 2015 a US\$ 4.894 millones en 2018, la participación de las exportaciones no minero-energéticas ha aumentado, pasando $38 \%$ a $47 \%$ respectivamente. $Y$ en el caso de la EFTA, pese a que las exportaciones totales de Colombia han disminuido constantemente de 2015 (US\$ 460 millones) a 2018 (US\$ 380 millones), la participación de las no minero-energéticas ha aumentado (de $13 \%$ a $20 \%$ respectivamente) ${ }^{54}$.

Tabla 2

Exportaciones no minero-energéticas de Colombia a socios comerciales con los que firmó TLCs a partir de 2011

\begin{tabular}{|c|c|c|c|c|c|c|c|c|c|}
\hline $\begin{array}{l}\text { 吉 } \\
\text { Ф๊̊ }\end{array}$ & 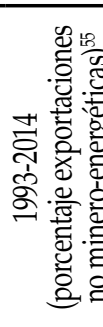 & 芯 & 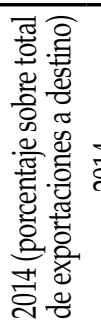 & 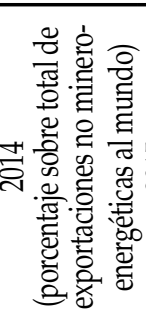 & 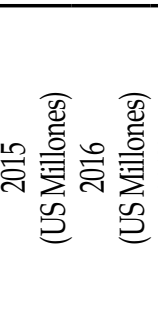 & 会总 & 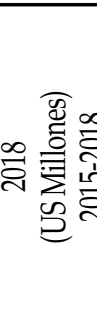 & 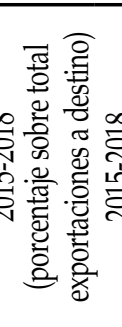 & 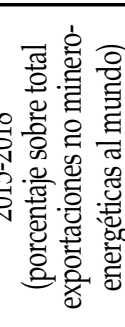 \\
\hline $\begin{array}{l}\text { Costa } \\
\text { Rica }\end{array}$ & $85 \%$ & 257 & $97 \%$ & $1,6 \%$ & 238 & 233 & 242 & $97 \%$ & $1,6 \%$ \\
\hline $\begin{array}{l}\text { Pan- } \\
\text { amá }^{57}\end{array}$ & $78 \%$ & 346 & $9 \%$ & $2,1 \%$ & 333 & 319 & 311 & $15 \%$ & $2 \%$ \\
\hline Israel $^{58}$ & $11 \%$ & 28 & $5 \%$ & $0,2 \%$ & 31 & 39 & 37 & $11 \%$ & $0,2 \%$ \\
\hline $\begin{array}{c}\text { Corea } \\
\text { del } \\
\text { Sur }^{59}\end{array}$ & $50 \%$ & 144 & $27 \%$ & $0,9 \%$ & 143 & 201 & 168 & $45 \%$ & $1 \%$ \\
\hline
\end{tabular}

Fuente: Elaboración propia, con base en ProColombia (2016b), Analdex (2018), DANE (2017), Jiménez, Leal y Suárez (2018), MinCIT (2019a, 2019b y2019c).

En 2014, Colombia suscribió acuerdos con Costa Rica, Panamá, Israel, Corea del Sur y la Alianza del Pacífico, los cuales se encuentran ya vigentes (excepto el de Panamá y el de Israel). Como puede observarse en la Tabla 2, estos nuevos socios presentan una participación más heterogénea como destinos de las exportaciones no minero-energéticas colombianas, las que además no tienen una representación importante en volumen (ninguno supera los US \$360 millones anuales). Si bien Costa Rica mantuvo una tendencia importante como destino de estas exportaciones entre 1993 y 2014, la ha aumentado significativamente en el periodo 2015-2018, lo cual indica que el TLC entrado en vigor en 2013 puede haber favorecido el aumento de las exportaciones no minero-energéticas a este destino. En cambio, Panamá ha transfor- 
mado radicalmente su tendencia, llegando a disminuirla de un 78\% entre 1993 y 2014 a un 15\% en el periodo 2015-2018, debido a que en los últimos años muchas de las exportaciones minero-energéticas colombianas se realizan a compañías intermediarias que tienen su sede en Panamá. Se esperaría que la entrada en vigencia de este tratado pudiera contrarrestar un poco esta tendencia, pero a la luz de los datos de los últimos años esto parece poco probable, al igual que ocurre con el caso del TLC con Israel, que en principio refuerza la tendencia reprimarizadora de la canasta exportadora colombiana.

Pero el caso de Corea del Sur es llamativo, por cuanto se han presentado importantes reservas por parte de algunos sectores exportadores colombianos sobre su conveniencia. De una parte, el déficit comercial con Corea del Sur ha sido significativo, alcanzando US\$984 millones en 2013 y US\$ 892 millones en 2014; y de otra, algunos de los principales productos que Colombia importa de Corea del Sur representan una competencia directa para productores colombianos, como por ejemplo los automóviles de turismo y para transporte de personas, los polímeros de etileno, los neumáticos nuevos de caucho, los polímeros acrílicos y los polímeros de propileno (MinCIT, 2015b:36). Es así que una de las empresas más importantes del sector automotriz en Colombia, la Compañía Colombiana Automotriz (ensambladora de Mazda), se fue del país a finales de 2014, y también el fabricante de neumáticos Icollantas-Michelin a mediados de 2013. En el caso de la primera, la Asociación Nacional de Empresarios de Colombia (ANDI) reconoció una amenaza explícita proveniente del TLC con Corea (El Tiempo, 2014), y en el de la segunda el presidente de Michelin Colombia (Icollantas) hizo referencia a la importación masiva de neumáticos asiáticos (sin mencionar específicamente a Corea del Sur) como una de las causas del cierre de la empresa (Portafolio, 2013). Aunque la tendencia de participación de exportaciones minero-energéticas y no minero-energéticas rondó un promedio de 50\% entre 1993 y 2014, entre 2015 y 2018 las exportaciones no minero-energéticas de Colombia hacia Corea del Sur disminuyeron a un promedio anual de $45 \%$ sobre el total exportado a este país, alcanzando un pico de $62 \%$ en 2015 y un piso de $27 \%$ en $2018^{60}$. En cuanto al déficit comercial con Corea del Sur, este continuó siendo significativo, alcanzando los US\$ 856 millones en 2015, US\$ 431 millones en 2016, US\$ 289 millones en 2017 y US\$ 148 millones en 2018. No está claro entonces por qué se decidió establecer un TLC con un país con el que se tiene un enorme déficit comercial (aunque disminuyó significativamente en 2018), y que, además, no 
sólo ejerce una fuerte presión reprimarizadora sobre las exportaciones colombianas, sino que sus exportaciones hacia Colombia mantienen una competencia directa con los productos colombianos.

Nótese que con los países de América del Norte también se han mantenido déficits comerciales (no tanto con los europeos), y tanto con ellos como con los bloques europeos ya mencionados existe competencia con productos nacionales por parte de algunos de los principales renglones de importación del país ${ }^{61}$. Sin embargo, EE.UU. y la UE son mercados muy significativos para las exportaciones colombianas, tanto minero-energéticas como no minero-energéticas, y esto hace que cobre sentido abrir el mercado nacional a competidores de esos países, dados los beneficios de acceso a mercados que obtienen los productos colombianos. En cuanto a Canadá y a EFTA, su participación como destino de las exportaciones totales de Colombia ha sido apenas superior a la de Corea del Sur (que rondan cada uno apenas el 1\% del total de exportaciones colombianas al mundo), pero con los dos primeros existe una tradición de relacionamiento comercial y político mucho mayor que con Corea del Sur. La pregunta que surge es: ¿por qué, si ya se tenían abiertos los mercados a competidores directos que no representan un destino significativo de exportaciones colombianas - caso Canadá y EFTA -, se siguen abriendo a países de iguales características, como Corea del Sur? Los casos de Turquía y Japón también son indicativos de esta falta de claridad en los criterios para firmar nuevos TLC por parte del gobierno colombiano.

Desde 2011 comenzaron las negociaciones de un TLC con Turquía, pero aun continúan en curso ${ }^{62}$. En 2014, de un total de US\$ 863 millones exportados, un $98 \%$ correspondió a bienes minero-energéticos. Entre 2015 y 2018 las exportaciones no minero-energéticas de Colombia a Turquía totalizaron apenas US\$15 millones, US\$ 8 millones, US\$ 13 millones y US\$ 7 millones respectivamente, lo que equivalió a un promedio anual de $0.1 \%$ del total de estas exportaciones al mundo, y un promedio de $0.9 \%$ del total exportado a ese país ${ }^{63}$, donde predominan las exportaciones de carbón. Estas cifras dan cuenta de la enorme presión reprimarizadora que tiene el comercio con Turquía, lo que abre esperanzas para que dicha oferta se pueda diversificar una vez se concrete el TLC. Un estudio señaló en 2013 que el principal producto colombiano con potencial de expandir su volumen de exportación a Turquía con un TLC era el banano, aunque identificó buenas perspectivas también para productos de las industrias químicas y conexas, 
plástico y caucho, productos minerales, y textiles y manufacturas de cuero (Gómez, Pereira y Gaitán, 2013). Sin embargo, en 2014 empresarios colombianos advertían sobre el riesgo de competencia para los productores nacionales con la entrada libre de productos turcos como las autopartes y los productos de confitería (La República, 2014), siendo de hecho los textiles, la maquinaria y equipo y las confecciones los primeros renglones de importaciones provenientes de Turquía en 2011 (MinCIT, 2015c:2). También algunos empresarios veían potencial para las exportaciones colombianas de cosméticos y flores (La República, 2014). En 2018, las preocupaciones de los empresarios colombianos por la "inundación" de productos turcos en el mercado doméstico continuaban (Semana, 2018).

Con Japón, las negociaciones se iniciaron en 2012 y aun siguen en curso. En 2013 Colombia exportó a este país un total de US\$ 388 millones, después de haber alcanzado picos de US\$ 511 y US\$ 528 millones en 2010 y 2011 (MinCIT, 2015d). Si bien las exportaciones minero-energéticas fueron de tan solo US $\$ 49$ millones, los productos primarios (sumando café, esmeraldas, flores y banano) representaron el 99.5\% del total de exportaciones colombianas a Japón. En 2014, las exportaciones no minero-energéticas completaron los US\$344 millones, correspondiendo al $88 \%$ del total exportado. Entre 2015 y 2018 estas exportaciones fueron de US \$ 400 millones, US\$ 338 millones, US\$ 359 millones y US\$292 millones respectivamente, equivaliendo a un porcentaje promedio anual de $2.4 \%$ del total de este tipo de exportaciones al mundo, y un promedio de $71 \%$ del total exportado a este país ${ }^{64}$. Esto da cuenta de los beneficios que el comercio con Japón trae para la diversificación de la oferta exportadora colombiana, aun cuando la gran mayoría de productos exportados sean bienes primarios como el café y el banano. Sin embargo, pese a que en su momento el gobierno colombiano identificó potenciales sectores de exportación que pueden beneficiarse de un TLC con Japón, tales como los jugos, confitería, bebidas lácteas y conservas, confecciones, cuero y calzado, también se identificaron posibles riesgos para los productores nacionales en los sectores automotriz, productos de caucho, vidrio y textiles (Recalca, 2014).

Finalmente, en los últimos años, la gran apuesta de regionalismo comercial de Colombia ha sido el acuerdo de la Alianza del Pacífico (AP), con México, Chile y Perú como socios cofundadores, y que ha significado muy poco en términos de liberalización comercial, por cuanto prácticamente la totalidad del comercio entre los cuatro países estaba 
ya liberalizada para 2014, año de la firma del Protocolo Comercial ${ }^{65}$. Después de haberse mantenido en niveles inferiores a los US\$2.000 millones entre 1993 y 2008, las exportaciones colombianas a los países de la AP comenzaron a incrementarse a partir de 2009 hasta llegar a los US\$ 4.606 millones en 2012, para luego situarse en US\$ 3.090 millones en 2014 (MinCIT, 2015b:75). Salvo los picos más bajos de 51\% en 2011 y 2012, la participación de las exportaciones no minero-energéticas en el total de exportaciones colombianas a Perú, México y Chile mantuvo niveles cercanos a un promedio del 70\%, situándose en $72 \%$ (US\$ 2.235 millones) en 2014 (MinCIT, 2015b:71). Entre 2015 y 2018 el total de exportaciones no minero-energéticas de Colombia a la AP alcanzó los US\$ 2.249 millones, US\$ 2.159 millones, US\$ 2.291 millones y US\$ 2.302 millones respectivamente, lo que equivale a un promedio anual del $15 \%$ del total de estas exportaciones al mundo, y un promedio del $70 \%$ sobre el total exportado a este bloque. ${ }^{66}$ Llama la atención que este porcentaje disminuyó significativamente del $80 \%$ y $81 \%$ en 2015 y 2016, al $62 \%$ y $58 \%$ en 2017 y 2018 , respectivamente, debido en particular al aumento de las exportaciones de carbón a México (MinCIT, 2019e). Si bien estas cifras demuestran el potencial de la AP para contribuir a la diversificación de la oferta exportadora colombiana, el hecho de que el comercio de bienes con estos países ya estuviese liberalizado casi en su totalidad, hace que los posibles incrementos que puedan presentarse en el valor de las exportaciones colombianas dependa más de un aumento de su demanda (que seguramente tendría que pasar por un aumento en su capacidad de compra) que de la "liberalización comercial" anunciada en 2014.

¿Cuáles pueden estar siendo, entonces, los criterios del gobierno colombiano para firmar TLCs? Se ha argumentado ya que es razonable hacerlo con los grandes compradores de exportaciones colombianas (América Latina, EE.UU., la UE), pero con países como Corea del Sur, Turquía y Japón, que no lo son, y que además presentan amenazas para la producción nacional y un potencial reprimarizador, los criterios no son claros. En cuanto a la AP, más que un aumento en los flujos comerciales, su potencial se vislumbra en la posibilidad de formar encadenamientos productivos regionales en algunos sectores para acumular origen ${ }^{67}$ y poder incrementar la competitividad de estos productos en mercados internacionales (Prieto, 2018). Sin embargo, esto está sujeto a grandes desarrollos institucionales que permitan la articulación de políticas de desarrollo productivo entre los cuatro países miembros, de lo cual la AP no ha dado hasta el momento muestra 
alguna (excepto el anuncio de trabajar en la acumulación de origen ${ }^{68}$, mas no en la definición de políticas conjuntas para la formación de encadenamientos productivos).

Por supuesto que es importante abrir mercados para los bienes minero-energéticos y primarios en los que Colombia es más competitivo, pero sin una estrategia complementaria de apertura de mercados en lugares que puedan demandar productos de mayor valor agregado (África, por ejemplo), y sobre todo sin estrategias que aumenten la competitividad de estos productos, tanto para hacer frente a la competencia de las importaciones como para ser exportados a esos países con quienes se firma TLCs, las posibilidades de que la política comercial colombiana tenga un impacto significativo sobre el desarrollo nacional son escasas. Es claro que existen obstáculos de tipo político y cultural para que la transformación productiva de Colombia se vuelva objeto de una política nacional. La cultura rentista de los grandes terratenientes, en parte heredada por ciertos grupos empresariales que trasladaron sus capitales agrícolas al sector manufacturero, contribuye a que tanto terratenientes como industriales se mantengan en una posición cómoda y privilegiada dentro de la pirámide socioeconómica colombiana, que a su vez los vuelve aversos al riesgo de invertir en nuevos sectores productivos. Por otra parte, muchos sectores productores de manufacturas se tornaron sectores importadores de bienes en los años 1990, y también es cierto que las condiciones de crédito para la inversión productiva en Colombia no son las más blandas, de modo de incentivar a los empresarios a dejar de priorizar sus negocios seguros ya existentes, para emprender en nuevas actividades productivas que generen mayor valor agregado.

A su vez, exportar commodities es insuficiente para el crecimiento y desarrollo económico porque no genera cadenas de valor y crea muy poco empleo. Si el objetivo es articular la firma de TLCs con la atracción de IED, el riesgo reprimarizador de atraer mayor IED a los sectores con mayor potencial exportador a los mercados con los que se firman TLCs es muy alto. El actual gobierno del presidente Iván Duque anunció desde su posesión que por el momento no negociaría nuevos TLC con otros países, sino que se concentraría en aprovechar los que ya existen (El Espectador, 2018) ${ }^{69}$. Pero sin contar con estrategias concretas de aprovechamiento de los acuerdos comerciales existentes y de atracción de IED a sectores estratégicos, las ESIEI de Colombia 
derivan en una inserción precaria en la economía mundial, donde las posibilidades de alcanzar mayores niveles de crecimiento y desarrollo económico permanecen lejanas.

\section{CONCLUSIÓN: LA DISPERSIÓN Y EL IMPACTO PRECARIO DE LAS ESIEI DE COLOMBIA}

La adopción del modelo neoliberal ha derivado en la desarticulación de la política comercial y de atracción de IED con objetivos de desarrollo claves, como la transformación productiva con miras a producir y exportar mayor valor agregado, y a generar más empleo y mejor remunerado. Colombia ha tenido un desempeño relativamente bueno en cuanto a volumen de atracción de IED, y mediano en cuanto a los índices de desempeño y de potencial de atracción durante la etapa de neoliberalismo, pero la IED se ha concentrado en el sector minero-energético y no ha tenido un impacto claro sobre el crecimiento económico. Por otra parte, Colombia ha sido activa en ampliar su proyección comercial a nivel regional y global con la firma de varios TLCs. Sin embargo, aparte de los TLCs con los países latinoamericanos, vitales para las exportaciones no tradicionales y no minero-energéticas de Colombia, y de los TLCs que se han firmado con EE.UU. y la UE para asegurar el acceso a los mercados que más demandan exportaciones colombianas, los TLC restantes no han respondido a un criterio claro ni de tamaño de mercado (en términos de demanda de exportaciones colombianas) ni de potencial diversificador de la canasta exportadora colombiana. Puede concluirse, por ende, que a través de las estrategias para atraer IED y obtener acceso a mercados para sus exportaciones, Colombia ha logrado una inserción económica internacional precaria, en tanto estas estrategias no han tenido un impacto significativo sobre el desarrollo económico, puesto que han reforzado el proceso reprimarizador de su economía y de su canasta exportadora, y su impacto sobre el crecimiento no ha sido claro en materia de IED.

A través de un ejercicio profundo de revisión de fuentes y agregación de cifras, el presente artículo ha ofrecido un panorama general, pero a la vez integral sobre los resultados e impacto de la estrategia de atracción de IED de Colombia y de su estrategia de firmar TLCs, con relación a las oportunidades que encuentran las exportaciones no minero-energéticas en esos mercados. No obstante, futuros trabajos que busquen realizar valoraciones similares podrían profundizar en la relación entre IED y TLCs, para lograr una mejor comprensión de la 
forma en que se han complementado ambas estrategias. Este tipo de valoraciones generales pero a la vez integrales es fundamental para ahondar en la necesaria reflexión sobre el desempeño del modelo de desarrollo vigente.

(Recibido el 16 de enero de 2020)

(Reenviado el 11 de mayo de 2020)

(Aprobado para su publicación el 7 de julio de 2020)

\section{NOTAS}

1. Según el MinCIT, el acuerdo con Perú entró en vigencia en diciembre de 2010, con Chile en mayo de 2009 y con el Reino Unido en octubre de 2014. Los acuerdos con Italia y Cuba no se reanudaron después de que la Corte Constitucional de Colombia declaró su inexequibilidad.

2. Por sus siglas en inglés (Bilateral Investment Treaty).

3. En cambio, el TLC con la UE no incluye un capítulo de inversión, aunque en los diversos apartados sí se incluyen disposiciones al respecto.

4. Cálculos propios con cifras del DANE - Producto Interno Bruto (PIB) Históricos Base 2005.

5. Cálculos propios con datos de CEPAL (2012; 2013; 2016).

6. De acuerdo a Garavito, Iregui y Ramírez (2012:39-40), “El índice de desempeño ordena los países de acuerdo a la IED que reciben con relación al tamaño de su economía. Se calcula como el cociente entre la participación de las entradas de IED a un país en las entradas globales de IED sobre su participación en el PIB mundial. Si el valor del índice es superior a 1, el país atrae más IED que la esperada de acuerdo al tamaño de su PIB [...] Por su parte, el índice de potencial de entradas de IED se calcula como el promedio simple de 12 variables: PIB per cápita, crecimiento del PIB de los últimos diez años, participación de las exportaciones en el PIB, el número promedio de líneas telefónicas y teléfonos celulares por cada 1.000 habitantes, el uso comercial de energía per cápita, la participación del gasto en investigación y desarrollo sobre el PIB, la participación de los estudiantes de educación terciaria en la población, un indicador de riesgo país, exportaciones de recursos naturales, importaciones de partes y componentes para automóviles y productos electrónicos, exportaciones de servicios y la participación del acervo de entradas de IED".

7. Cálculos propios con datos de ProColombia (2015) y Banco de la República (2015 y 2018a).

8. Cálculos propios con datos de ProColombia (2015) y Banco de la República (2015 y 2018a). El promedio no se refiere obviamente al promedio anual, sino a la sumatoria de los años dividida por 4, tomando como base el año 2010. Lo mismo aplica para las notas 9 y 10.

9. Cálculos propios con datos de ProColombia (2015) y Banco de la República (2015 y 2018a).

10. Cálculos propios con datos de ProColombia (2015) y Banco de la República (2015 y 2018a). 
11. Cálculos propios con datos del Banco de la República (2015), a precios constantes de 2005.

12. Cálculos propios con datos del Banco de la República (2015), a precios constantes de 2005.

13. Cálculos propios con datos del Banco Mundial (2019) a precios constantes de 2010.

14. Alfonso (2012:43), por ejemplo, sostiene que entre 1996 y 2011 la IED no tuvo un impacto significativo sobre el crecimiento del PIB en Colombia, a excepción, si acaso, del periodo 1996-2000, donde si se reduce el nivel de confianza sí sería posible establecer estadísticamente que un aumento de US\$100 millones en la IED incrementaría en $0.91 \%$ el PIB. Sin embargo, la autora atribuye esta significancia estadística a la crisis económica y la consecuente escasez de recursos para inversión que se vivió en este periodo, en particular en los años 1999 y 2000.

15. Por supuesto, no puede decirse lo mismo para el acervo de IED, que se refiere a la riqueza generada por la IED a través de los años, y que en párrafos anteriores se ha mostrado que ha oscilado alrededor del $30 \%$ del PIB. Sin embargo, debe tenerse en cuenta que esta riqueza generada en el largo plazo no depende tanto de la IED recibida en un momento dado, sino del desempeño de la economía en general durante ese largo plazo, dentro de lo cual cuenta por supuesto la IED recibida cada año, pero no se reduce a ello.

16. Cálculos propios con datos de ProColombia (2015).

17. Cálculos propios con datos de Banco de la República (2018b).

18. Cálculos propios con datos de ProColombia (2015).

19. Cálculos propios con datos de Banco de la República (2018b).

20. Cálculos propios con datos de ProColombia (2015).

21. ProColombia (2015) distingue los siguientes sectores que aquí han sido agregados dentro del sector "servicios": Transportes, Almacenamiento y Comunicaciones; Servicios Financieros y Empresariales; Comercio, Restaurantes y Hoteles; Electricidad, Gas y Agua; Construcción; y Servicios Comunales. A. Garavito, Iregui y Ramírez (2012) no discriminan sus cifras por sectores.

22. Cálculos propios con datos de Banco de la República (2018b).

23. Martínez (2011:57) define la desindustrialización como "la pérdida de participación del PIB y el empleo industrial dentro del PIB y el empleo total".

24. Cálculos propios con datos de Banco de la República (2019a).

25. Cálculos propios con datos de Banco de la República (2019b).

26. Cálculos propios con datos de Banco de la República (2019b).

27. Es decir, la participación del empleo industrial sobre el total de empleos excluyendo aquellos del sector agropecuario.

28. Barranquilla, Bogotá, Bucaramanga, Cali, Cartagena, Manizales, Medellín y Pereira.

29. Cálculos propios con datos de DNP (2019).

30. Cálculos propios con datos de DNP (2019). 
31. Asociación Europea de Libre Comercio, compuesta por Suiza, Liechtenstein, Noruega e Islandia.

32. Por sus siglas en inglés Trade in Services Agreement.

33. Basada en los índices PRODY y EXPY de Hausmann, Hwang y Rodrik (2007), citado en Martínez y Suárez (2011:66).

34. No obstante, en ninguno de estos países se encontró un peso representativo de las manufacturas de alta tecnología en el valor de las exportaciones. Martínez y Suárez (2011:82) se basan en Lall (2000), quien propone una clasificación de los productos exportados de acuerdo con su nivel tecnológico en 5 grupos: productos primarios, manufacturas basadas en recursos (agropecuarios, otros), manufacturas de baja tecnología (textiles, vestuario y calzado, otros productos), manufacturas de mediana tecnología (automotrices, de proceso, ingeniería) y manufacturas de alta tecnología (eléctricas y electrónicas, otras).

35. Cálculos propios con datos de Banco de la República (2019b).

36. Aquéllas diferentes a café, carbón, ferroníquel, petróleo y sus derivados. A partir de 2013, se excluyó también al oro de las exportaciones no tradicionales (es decir, pasó a considerarse parte de las tradicionales). Nótese que no deben confundirse las exportaciones no tradicionales con las manufactureras o con algún nivel de componente tecnológico. El banano y las flores, por ejemplo, son consideradas exportaciones no tradicionales en Colombia, aunque estos dos productos no ocupan un lugar importante dentro de las exportaciones de Colombia hacia América Latina (Prieto, 2011).

37. Exceptuando Nicaragua, Cuba y CARICOM, debido a su escasa participación como destino de las exportaciones colombianas (incluyendo productos minero-energéticos y no minero-energéticos).

38. Excepto Nicaragua, Cuba y CARICOM.

39. Cálculos propios con datos de MinCIT (2015a).

40. Bolivia, Ecuador y Perú. No incluye Venezuela.

41. Cálculos propios con datos adicionales de MinCIT (2019a) y DANE (2019a).

42. Cálculos propios con datos de Procolombia (2016a) y DANE (2016) para el año 2015, y Analdex (2018) y MinCIT (2019a y 2019b) para los años 2016-2018.

43. Excepto nota 44, cálculos propios con datos Procolombia (2016a), DANE (2019a) y Analdex (2018) para el año 2015, y MinCIT (2019a y 2019b) para los años 2016-2018.

44. Cálculos propios con datos de DANE (2019a), Analdex (2018) y MinCIT (2019a).

45. Cálculos propios con datos de Analdex (2018) y Rodríguez $(2016,38)$ para el año 2015, y DANE (2019a y 2019b), Analdex (2018) y MinCIT (2019a y 2019b) para los años 2016-2018.

46. Cálculos propios con datos de Procolombia (2016a), DANE (2019a), Analdex (2018) y MinCIT (2019a).

47. Guatemala, Honduras y El Salvador. Cálculos propios con datos de CEPEC (2017) y Analdex (2018) para el año 2015, MinCIT (2019a y 2019b), y Analdex (2018) para los años 2016-2018.

48. Cálculos propios con datos de CEPEC (2017), Analdex (2018) y MinCIT (2019a). 
49. Cálculos propios con datos de CEPEC (2017), Analdex (2018) y MinCIT (2019a).

50. Cálculos propios con datos de CEPEC (2017), Analdex (2018) y MinCIT (2019a).

51. Cálculos propios con datos de CEPEC (2017), Analdex (2018) y MinCIT (2019a).

52. Departamento Administrativo Nacional de Estadística (DANE), Boletín técnico Exportaciones - EXPO (Diciembre 2017) (2018:19)

53. Cálculos propios con datos de ProColombia (2016a).

54. Cálculos propios con datos de CEPEC (2017), Analdex (2018) y MinCIT (2019a).

55. Cálculos propios con datos de MinCIT (2015b).

56. Cálculos propios con datos de ProColombia (2016b), Analdex (2018) y MinCIT (2019a y 2019b).

57. Cálculos propios con datos de MinCIT (2016 y 2019c) y Analdex (2018).

58. Cálculos propios con datos de Jiménez, Leal y Suárez (2018), MinCIT (2019c) y Analdex (2018).

59. Cálculos propios con datos de DANE (2017) ya se incluyó en las referencias [no localizado en las referencias], MinCIT (2019c) y Analdex (2018).

60. Cálculos propios con datos de INCP (2017), MinCIT (2019b) y Analdex (2018).

61. Plásticos y papel con Canadá; arroz, plásticos y abonos con EE.UU.; abonos minerales o químicos con EFTA; y automóviles y papel con la UE (análisis propio con datos tomados de MinCIT 2015a).

62. Tal y como aparece en estado de negociación en la página web del MinCIT (2019d).

63. Cálculos propios con datos MinCIT (2014; 2019b), ProColombia (2017) y Analdex 2018.

64. Cálculos propios con datos MinCIT (2016; 2019c) y Analdex 2018.

65. Este Protocolo se firmó en febrero de 2014, y con él se anunció que se liberalizaba el $92 \%$ del universo arancelario y el restante en un plazo de 15 años, el cual corresponde esencialmente a bienes agrícolas. Este anuncio fue más bien engañoso, por cuanto ese $92 \%$ ya estaba prácticamente liberalizado a través de los acuerdos de Colombia con Perú (CAN), con México (G-3), con Chile (TLC); de Chile con México (TLC) y con Perú (TLC); y de México con Perú (TLC).

66. Cálculos propios con datos CEPEC (2017), MinCIT (2019a) y Analdex 2018.

67. El BID identificó algunos productos con algún componente tecnológico que podrían ser objeto de encadenamientos productivos entre los países de la AP: fibras y alfombras de poliéster entre Perú y Chile; fosfatos y detergentes entre México y Perú; pasta química de madera y papel, y cartón entre Chile y Colombia; y polímeros de propileno y envases de plástico entre Colombia y México (El Comercio, 2014).

68. Ver por ejemplo Andina (2016).

69. Y, se asume, terminar de negociar los que se encuentran en curso, pues de lo contrario se hubiera anunciado una suspensión de las negociaciones con Turquía y Japón, cosa que no ha ocurrido. 


\section{REFERENCIAS}

ALFONSO, Laura Alejandra. (2012), “La inversión extranjera directa: ¿oportunidad o amenaza?”. Revista Civilizar, Ed. 5, pp. 34-61. Disponible en: http:/ / www.usergioarboleda. edu.co/civilizar/economia/edicion-5/N.5\%20ART.2.pdf. Accedido el 12 de julio de 2019.

ASOCIACIÓN NACIONAL DE EXPORTADORES (ANALDEX). (2018), Informe de Comercio Exterior 2017. Disponible en: http:/ /www.analdex.org/wp-content/ uploads /2018/02/2018-02-23-Informe-de-Comercio-Exterior-2017.pdf. Accedido el 15 de julio de 2019.

BANCO MUNDIAL. (2019), Datos. PIB per cápita (US\$ a precios constantes de 2010), Colombia. Disponible en: https:/ / datos.bancomundial.org/indicator/NY.GDP.PCAP. KD?locations=CO\&view=chart. Accedido 14 de julio de 2019.

BANCO DE LA REPÚBLICA. (2015), Estadísticas, PIB, producción, salarios y empleo. Disponible en: http:/ / www.banrep.gov.co/es/info-temas-a/4024. Accedido el 16 de julio de 2019.

. (2018a), IED (millones de dólares). Subgerencia de Política Monetaria e Información Económica. Disponible en: http:/ / www.banrep.gov.co/es/inversion-directa. Accedido el 16 de julio de 2019.

. (2018b), Informe de Inversión Extranjera directa en Colombia según actividad económicaanual desde 1994 y trimestral desde 1996 (2018). Disponible en: http: / /www.banrep.gov. co/es/inversion-directa. Accedido el 15 de julio de 2019.

. (2019a), PIB a precios constantes de 2015 grandes ramas de actividad económica, Miles de millones de pesos. Disponible en: http:/ / www.banrep.gov.co/es/pib. Accedido el 15 de julio de 2019.

. (2019b), PIB a precios corrientes grandes ramas de actividad económica, Variaciones \% anuales. Disponible en: http:/ / www.banrep.gov.co/es/pib. Accedido el 16 de julio de 2019.

CENTRO DE ESTUDIOS LATINOAMERICANOS (CESLA). (2019), “La Inversión Extranjera Directa en Latinoamérica". Informe semestral, no 7, Mayo. Disponible en: https:/ /www. cesla.com/pdfs/Informe-IED-en-Latinoamerica.pdf. Accedido el 15 de julio de 2019.

CENTRO DE PENSAMIENTO DE ESTRATEGIAS COMPETITIVAS (CEPEC). (2017), Evolución de exportaciones con países que tienen acuerdos comerciales con Colombia (2006-2017). Bogotá: Universidad del Rosario. Disponible en: https:/ / www.urosario.edu.co/competitividad/contenido/Publicaciones/Informe-especial-TLCs_17agosto-VF-3.pdf. Accedido el 16 de julio de 2019.

CEPAL. (2012), La Inversión Extranjera Directa en América Latina y el Caribe. Documento Informativo. Disponible en: http://www10.iadb.org/intal/intalcdi/PE/2013/11869es.pdf. Accedido el 14 de julio de 2019.

. (2013), La Inversión Extranjera Directa en América Latina y el Caribe. Documento Informativo. Disponible en: https://repositorio.cepal.org/bitstream/handle/11362/36805/1/ S1420131_es.pdf. Accedido el 13 de julio de 2019.

. (2016), La Inversión Extranjera Directa en América Latina y el Caribe 2016. Documento Informativo. Disponible en: https:/ / www.cepal.org/es/publicaciones/40213-la-inversion-extranjera-directa-america-latina-caribe-2016. Accedido el 14 de julio de 2019. 
DE LOMBAERDE, Philippe; GARAY, Luis Jorge. (2009), "FDI Policies in times of conflict: the case of Colombia". UNU-CRIS Working Papers: W-2009/23. Disponible en: http:/ /www. cris.unu.edu/fileadmin/workingpapers/W-2009-23.pdf. Accedido el 3 de junio de 2019.

DEPARTAMENTO ADMINISTRATIVO NACIONAL DE ESTADÍSTICA (DANE). Producto Interno Bruto (PIB) Históricos Base 2005. Disponible en: https:/ /www.dane.gov.co/index.php/estadisticas-por-tema/cuentas-nacionales/cuentas-nacionales-trimestrales / historicos-producto-interno-bruto-pib\#base-2005. Accedido el 14 de julio de 2019.

. (2016), Boletín técnico:Comercio Exterior-Exportaciones Diciembre de 2015 (Preliminar). Disponible en: https://www.dane.gov.co/files/investigaciones/boletines/exportaciones/bol_exp_dic15.pdf. Accedido el 12 de julio de 2019.

. (2018), Boletín técnico Exportaciones - EXPO (Diciembre 2016). Disponible en: https:// www.dane.gov.co/files/investigaciones/boletines/exportaciones/bol_exp_dic16.pdf. Accedido el 13 de julio de 2019.

. (2018), Boletín técnico Exportaciones - EXPO (Diciembre 2017). Disponible en: https:// www.dane.gov.co/files/investigaciones/boletines/exportaciones/bol_exp_dic17.pdf. Accedido el 14 de julio de 2019.

. (2019a), Exportaciones, Colombia destino de las exportaciones 1994-2019p (abril). Disponible en: https:/ / www.dane.gov.co/index.php/estadisticas-por-tema/comercio-internacional/exportaciones. Accedido el 17 de julio de 2019.

DEPARTAMENTO NACIONAL DE PLANEACIÓN (DNP). (2019), Estadísticas Sectoriales, Mercado Laboral - Población por rama de actividad, posición ocupacional, edad de trabajar, ocupados, desocupados y sexo (2001-2017). Disponible en: https:/ / www.dnp.gov.co/programas/agricultura/estadisticas-del-sector-agropecuario/Paginas/Sectoriales.aspx. Accedido el 15 de julio de 2019.

FEDESARROLLO (Fundación para la Educación Superior y el Desarrollo). (2007), Impacto de la inversión extranjera en Colombia: Situación actual y perspectivas. Proyecto elaborado por FEDESARROLLO para PROEXPORT. Informe final. Diciembre. Disponible en: http:/ / www.fedesarrollo.org.co/wp-content/uploads/2011/08/Impacto-de-la-inversi\%C3\%B3n-extranjera-en-Colombia-Informe-Final-Proexport-Dic-de-2007-_Impreso_.pdf. Accedido el 4 de junio de 2019.

GARAVITO, Aarón; IREGUI, Ana María; RAMíREZ, María Teresa. (2012), “Inversión extranjera directa en Colombia: evolución reciente y marco normativo". Borradores de Economía, n 713. Bogotá: Banco de la República. Disponible en: http:/ / www.banrep.gov.co/sites / default/files/publicaciones/archivos/be_713.pdf. Accedido el 14 de abril de 2019.

GARZÓN, Jorge F.; PRIETO, Germán C. (2017), Estrategias de inserción económica internacional de Colombia y Brasil: regionalismo cruzado y estrategia de tamaño. En: D. Flemes; E. Pastrana; M. Carpes (eds.) Estado y Perspectivas de las Relaciones Colombo-Brasileñas. Bogotá: Editorial Javeriana, pp. 119-146.

GÓMEZ, Daniel; PEREIRA, Catherine María; GAITÁN, Loly-Aylú. (2013), "Impacto de un TLC en el comercio entre Colombia y Turquía". Cuadernos de Administración, vol. 26, $\mathrm{n}^{\circ}$ 46, pp. 159-199. Disponible en: http:/ / www.scielo.org.co/scielo.php?pid=S0120-35922013000100008\&script=sci_arttext. Accedido el 13 de julio de 2019. 
HAUSMANN, Ricardo; HWANG, Jason; RODRIK, Dani. (2007), "What you export matters". Journal of Economic Growth, vol. 12, no 1, pp. 1-25. Disponible en: http:/ / www.jstor.org/ stable/40216112. Accedido el 3 de abril de 2019.

JIMÉNEZ, Daniel; LEAL, Parmenio; SUÁREZ, Zuly. (2018), Diagnóstico de los pilares del tratado de libre comercio entre Colombia e Israel en el ámbito comercial. Trabajo de grado, Universitaria Agustiniana, Facultad de Ciencias Económicas y Administrativas, Programa de Negocios Internacionales, Bogotá D.C. Disponible en: http:/ / repositorio. uniagustiniana.edu.co/handle/123456789/393. Accedido el 20 de julio de 2019.

KALIN, Ylva. (2009). "FDI in Colombia: policy and economic effects". Documento CEDE No. 25, noviembre, Bogotá: Universidad de Los Andes. Disponible en: http:/ / papers.ssrn. com/sol3/papers.cfm?abstract_id=1543787. Accedido el 10 de abril de 2019.

LALL, Sanjaya. (2000). "The technological structure and performance of developing country manufactured exports, 1985-98". Oxford Development Studies, vol. 28, nº 3, pp. 337-369.

MARTÍNEZ, Astrid. (2011), “La desindustrialización en Colombia 1990-2010”. En: J. A. Ocampo; A. Martínez (eds.), Hacia una política industrial de nueva generación para Colombia. Bogotá: Coalición para la Promoción de la Industria Colombiana, pp. 57-64.

; SUÁREZ, Nicolás. (2011), “Crecimiento económico y perfil exportador”. En: J. A. Ocampo; A. Martínez (eds.), Hacia una política industrial de nueva generación para Colombia. Bogotá: Coalición para la Promoción de la Industria Colombiana, pp.65-87.

MEJÍA, Andrés. (1998), “La diversificación de la inversión extranjera directa en Colombia: Respaldo económico para una mayor autonomía”. En: J. Tokatlian (ed.), Colombia y Estados Unidos problemas y perspectivas. Bogotá: COLCIENCIAS-IEPRI, TM editores, pp. 356-376.

MinCIT (Ministerio de Comercio, Industria y Turismo de Colombia). (2014), Exportaciones colombianas Enero-diciembre 2014. Disponible en: http:/ /www.sice.oas.org/ctyindex/ COL/Exports_2014_s.pdf. Accedido el 4 de mayo de 2019.

(2015a), Comercio exterior colombiano: seguimiento a los Acuerdos Comerciales, Oficina de Estudios Económicos. Disponible en: http:/ / www.mincit.gov.co/tlc/publicaciones. php?id=7246 (Acuerdos comerciales vigentes). Accedido el 4 de mayo de 2019.

. (2015b), Comercio exterior colombiano: seguimiento a los Acuerdos Comerciales, Oficina de Estudios Económicos. Disponible en: http:/ / www.mincit.gov.co/tlc/publicaciones. php?id=7246 (Acuerdos comerciales firmados y negociados). Accedido el 4 de mayo de 2019.

(2015c), Acuerdo Comercial entre Colombia y Turquía (Perfil Comercial y Económico). Disponible en: http:/ / www.tlc.gov.co/publicaciones.php?id=685. Accedido el 24 de julio de 2019.

. (2015d), Exportaciones Anuales (Japón). Disponible en: http:/ /www.mincit.gov.co/ publicaciones.php?id=10438. Accedido el 23 de julio de 2019.

. (2016). Información Exportaciones diciembre 2016 Total 2016, Oficina de Estudios Económicos. Disponible en: http://www.mincit.gov.co/getattachment/estudios-economicos/estadisticas-e-informes/informes-de-exportacion/2016/diciembre/dic_exportacion_2016.pdf.aspx. Accedido el 24 de julio de 2019. 
. (2019a), Seguimiento acuerdos comerciales vigentes. Disponible en: http:/ / www.mincit. gov.co/CMSPages/GetFile.aspx?guid=8c968447-f866-453c-8be5-0480df7e624f. Accedido el 21 de julio de 2019 .

. (2019b), Estadísticas Económicas Intercambiables, Sección 6: Comercio de Colombia con países con tratados comerciales vigentes. Disponible en: http:/ / www.mincit.gov.co/estudios-economicos/estadisticas-e-informes / sistemas-de-estadisticas-de-consulta-rapida/ estadisticas-economicas-intercambiables-indice. Accedido el 24 de julio de 2019.

. (2019c), Estadísticas Económicas Intercambiables, Sección 7: Exportaciones de Colombia. Disponible en: http:/ / www.mincit.gov.co/estudios-economicos/estadisticas-e-informes / sistemas-de-estadisticas-de-consulta-rapida/estadisticas-economicas-intercambiables-indice. Accedido el 23 de julio de 2019.

. (2019d), TLC Colombia Negociación en curso. Disponible en: http:/ / www.tlc.gov.co/ acuerdos/negociaciones-en-curso. Accedido el 25 de julio de 2019.

. (2019e), Alianza del Pacífico, Oficina de Estudios Económicos. Disponible en: http:/ / www.mincit.gov.co/CMSPages/GetFile.aspx?guid=da538111-cef8-40a6-89ea-c88cc763470e. Accedido el 24 de julio de 2019.

NOVA, Mariluz. (2014), “Análisis económico-político de la balanza de pagos de Colombia (1994-2013)". Revista Finanzas y Política Económica, vol. 6, nº 2, pp. 367-385.

PRIETO, Germán Camilo. (2011), "Futuro comercial de Colombia frente a América Latina". Policy Paper No. 38, Friedrich Ebert Stiftung en Colombia (FESCOL). Disponible en: http:/ / www.fescol.org/index.php?option=com_content\&view=article\&id=211:policy-paper-no-38\&catid=20:colombia-internacional\&Itemid=9. Accedido el 23 de abril de 2019.

; DEFELIPE, Camilo. (2015), "Política Exterior Económica en un escenario de postacuerdo: necesidades de transformación productiva y de mayor equidad social en Colombia". En: E. Pastrana; H. Gehring (eds.), Política exterior colombiana. Escenarios y desafíos en el posconflicto. Bogotá: Editorial Javeriana; Konrad Adenauer Stiftung (KAS), pp. 179-222.

PRIETO, Germán Camilo. (2016), Identidad colectiva e instituciones regionales en la Comunidad Andina: un análisis constructivista. Bogotá: Editorial Javeriana.

. (2018), “Cadenas de valor en la Alianza del Pacífico: posibilidades de inserción internacional para el desarrollo productivo". En: E. Pastrana; H. Blomeier (eds.), La Alianza del Pacífico: ¿atrapada en el péndulo del regionalismo y del interregionalismo? Bogotá: Konrad Adenauer Stiftung, pp. 247-278.

; BETANCOURT, Ricardo. (2014), “Entre la soberanía, el liberalismo y la innovación: un marco conceptual para el análisis de la Alianza del Pacífico". En: E. Pastrana; H. Gehring (eds.), Alianza del Pacífico: mitos y realidades. Cali: Universidad Santiago de Cali; Bogotá: Fundación Konrad Adenauer (KAS), pp. 75-113.

PROCOLOMBIA. (2015), Estadísticas de Inversión Extranjera Directa en Colombia. Disponible en: http:/ / www.inviertaencolombia.com.co/images/Estad\%C3\%ADsticas_de_IED_ en_Colombia_a_2014_-_Invierta_en_Colombia.pdf. Accedido el 14 de junio de 2019.

. (2016a), Análisis de las exportaciones colombianas: Informe enero-octubre de 2016. Disponible en: http:/ / www.procolombia.co/system/files/analisis_de_exportaciones_colombianas_enero_a_octubre.pdf?download=1. Accedido el 14 de junio de 2019. 
- (2016b), Acuerdo Comecial Colombia-Costa Rica. Oportunidades de negocios con una economía líder de Centroamérica. Disponible en: http:/ / www.procolombia.co/sites/default/ files/2016_acuerdo-comercial-costa-rica.pdf. Accedido el 15 de junio de 2019.

. (2017), Resumen Tres Ejes Turquía (Abril 2017). Disponible en: embajadas.procolombia. co/wp-content/uploads/2017/.../Tres_ejes_Turquia_2017.pdf. Accedido el 15 de junio de 2019.

REINA, Mauricio. (2016), Impacto económico de la inversión extranjera directa en Colombia 20072015. Bogotá: Fedesarrollo.

RODRÍGUEZ, Álvaro. (2016), El desafío del libre comercio entre Colombia y el Mercosur, Trabajo de Grado de Maestría. Universidad Militar Nueva Granada, Bogotá. Disponible en: https: / / repository.unimilitar.edu.co/bitstream/handle/10654/16122/RodriguezRodriguezAlvaro2017.pdf;jsessionid=E84C2226DD0C0D43072C52A33A2D045A?seq uence=3. Accedido el 15 de julio de 2019.

SISTEMA DE INFORMACIÓN SOBRE COMERCIO EXTERIOR (SICE). (2019), Información sobre Colombia, Tratado Bilaterales de Inversión. Organización de los Estados Americanos. Disponible en: http://www.sice.oas.org/ctyindex/COL/COLBITs_s.asp. Accedido el 13 de junio de 2019.

\section{Prensa}

Andina. (2016), "Acumulación de origen de Alianza del Pacífico creará cadenas regionales de valor". 22 de junio. Disponible en https: / / andina.pe/agencia/noticia-acumulacion-origen-es-una-las-ventajas-mas-importantes-alianza-del-pacifico-618288.aspx. Accedido el 21 de julio de 2019.

El Comercio. (2014), "Alianza del Pacífico: el BID identificó 8 cadenas productivas". 11 de febrero. Disponible en: http:/ / elcomercio.pe/economia/mundo/alianza-pacifico-bid-identifico-8-cadenas-productivas-noticia-1708722. Accedido el 20 de mayo de 2019.

El Espectador. (2018), "Duque reitera que en su gobierno no se firmarán nuevos TLC". 25 de julio. Disponible en: https: / / www.elespectador.com/economia/duque-reitera-que-en-su-gobierno-no-se-firmaran-nuevos-tlc-articulo-802385. Accedido el 19 de julio de 2019.

El Tiempo. (2014), "Hay crisis estructural en la industria automotriz, según la Andi". 31 de marzo. Disponible en: http:/ / www.eltiempo.com/archivo/documento/CMS-13758296. Accedido el 15 de julio de 2019.

La República. (2014), "El tratado comercial con Turquía aún está sin luz verde por el acceso a los mercados". 28 de abril. Disponible en: http:/ / www.larepublica.co/el-tratado-comercial-con-turqu\%C3\%ADa-aún-está-sin-luz-verde-por-el-acceso-los-mercados_114721. Accedido el 15 de julio de 2019.

Portafolio. (2013), "Se desinfla Michelin en el país: cierra Icollantas". 12 de junio. Disponible en: http:/ / www.portafolio.co/negocios/michelin-dejara-producir-colombia. Accedido el 13 de julio de 2019.

Recalca. (2014), “TLC con Japón: Una Derrota Anunciada”. 17 de septiembre. Disponible en: de http:/ / www.recalca.org.co/tlc-con-japon-una-derrota-anunciada/. Accedido el 14 de julio de 2019.

Semana. (2018), "TLC con Turquía asusta a empresarios colombianos". 26 de marzo. Disponible en: https://www.semana.com/economia/articulo/tlc-con-turquia-asusta-a-empresarios-colombianos/561637. Accedido el 16 de julio de 2019. 


\title{
RESUMO
}

As Estratégias de Inserção Econômica Internacional da Colômbia: Uma Avaliação do Investimento Estrangeiro Direto e dos Tratados de Livore Comércio

Por meio de análises de dados quantitativos de diversas fontes, o presente artigo demonstra que a Colômbia tem mantido uma estratégia homogênea de atração de investimento estrangeiro, mas a ausência de políticas de desenvolvimento produtivo em áreas específicas faz com que este investimento se concentre no setor mineiro-energético. Além disso, a assinatura de tratados de livre comércio tem sido dispersa, sendo que a política comercial tem permanecido desarticulada de objetivos de desenvolvimento e transformação produtiva, o que contribui para a reprimarização da estrutura produtiva e exportadora colombiana. A dispersão e o caráter difuso dessas duas estratégias têm gerado uma inserção econômica internacional precária da Colômbia, em relação ao seu impacto sobre o desenvolvimento econômico do país. Esta avaliação contribui com a literatura existente ao relacionar dados de distintas fontes e cobrir um período amplo, com o qual se aprofunda na avaliação das estratégias de inserção econômica da Colômbia.

Palavras-chave: inserção econômica internacional; investimento estrangeiro direto; Tratados de Livre Comércio; reprimarização; Colômbia

\begin{abstract}
Colombia's International Economic Insertion Strategies: An Appraisal of the Foreign Direct Investment and Free Trade Agreements

Through the analysis of quantitative data from various sources, this article shows that Colombia has maintained a homogenous strategy for attracting foreign investment, but the absence of productive development policies in specific areas has led this investment to concentrate on the mining and energy sector. Likewise, Colombia's strategy of signing Free Trade Agreements (FTAs) has been unfocused, inasmuch as trade policy has remained disjointed from productive transformation and development aims, which has, in turn, contributed to reprimarization of the country's productive and export structure. The dispersal of both strategies has generated a precarious international economic insertion for Colombia, particularly on its impact on economic development. This assessment contributes to the existing literature in putting together data from different sources and covering a broad period, which helps to deepen the analysis of Colombia's strategies of economic insertion.
\end{abstract}

Keywords: international economic insertion; foreign direct investment; free trade agreements; reprimarization; Colombia 


\section{RÉSUMÉ}

Les Stratégies d'Insertion Économique Internationale de la Colombie: Une Évaluation de l'Investissement Direct Étranger et des Accords de Libre-Échange

À travers l'analyse de données quantitatives provenant de diverses sources, cet article montre que la Colombie a maintenu une stratégie homogène pour attirer les investissements étrangers, mais l'absence de politiques de développement productif dans des domaines spécifiques a conduit cet investissement à se concentrer dans le secteur minier-énergétique. De même, la stratégie colombienne de signature des Accords de Libre-Échange (ALE) n'a pas été ciblée, car la politique commerciale est restée disjointe des objectifs de transformation productive et de développement, ce qui a à son tour contribué à la reprimarisation de la structure de production et d'exportation du pays. La dispersion des deux stratégies a généré une situation précaire d'insertion économique internationale pour la Colombie, notamment sur son impact sur le développement économique du pays. Cette évaluation contribue à la littérature existante en rassemblant des données provenantes de différentes sources et couvrant une large période, ce qui permet d'approfondir l'analyse des stratégies d'insertion économique de la Colombie.

Mots-clés: insertion economique internationale; l'investissement étranger direct; les accords de libre-échange; reprimarisation; Colombie

\section{RESUMEN}

Las Estrategias de Inserción Económica Internacional de Colombia: Una Valoración de la Inversión Extranjera Directa y de los Tratados de Libre Comercio

Por medio del análisis de datos cuantitativos de fuentes diversas, el presente artículo muestra que Colombia ha mantenido una estrategia homogénea de atracción de inversión extranjera, pero la ausencia de políticas de desarrollo productivo en áreas específicas ha hecho que esta inversión se haya concentrado en el sector minero-energético. Asimismo, la firma de tratados de libre comercio ha sido dispersa, en tanto la política comercial ha permanecido desarticulada de objetivos de desarrollo y transformación productiva, lo que ha contribuido a la reprimarización de la estructura productiva y exportadora colombiana. La dispersión y el carácter difuso de estas dos estrategias han generado que la inserción económica internacional de Colombia haya sido precaria en cuanto a su impacto sobre el desarrollo económico del país. Esta valoración contribuye a la literatura existente al relacionar datos de distintas fuentes y cubrir un periodo amplio, con lo cual se profundiza la valoración de las estrategias de inserción económica de Colombia.

Palabras clave: inserción económica internacional; inversión extranjera directa; tratados de libre comercio; reprimarización; Colombia 